\title{
Narraciones televisivas en tiempos de crisis: Irak $1998^{1}$
}

\section{TV stories in ages of crisis: Iraq 1998}

Jocelyne Arquembourg

Universidad de París II

ifp@u-paris2.fr

\section{Resumen}

A pesar del carácter extenso y discontinuo de la cobertura mediática a los conflictos bélicos que involucran a Irak desde 1990 hasta el presente, es posible concebir esta cobertura como un relato articulado sobre la base de "episodios" que nuclean acontecimientos. Mediante las tesis de Ricoeur y Dewey se estudia la operación "Zorro del desierto" (1998), que recoge tramas discursivas de la Guerra del Golfo a la vez que anticipa elementos de la cobertura a la invasión norteamericana de 2003. Así, se estudia cómo se construyen nudos narrativos a partir del flujo de informaciones y cómo, a través de estos episodios noticiosos, los medios de televisión franceses emiten juicios $-\mathrm{y}$ construyen sentido- sobre los actores involucrados, sus relaciones y la importancia general del conflicto.

Palabras clave: Televisión, Francia, Irak, relatos mediáticos.

\begin{abstract}
Despite the extensive and discontinuous nature of the media coverage on wars involving Iraq since 1990 to present, it is possible to concieve this coverage like an articulated narration based on "episodes" that centered events. By Ricoeur's and Dewey's theses, the paper studied the "Desert Fox" operation (1998), wich collects discursives frames of the Gulf War as well as anticipated elements of the media coverage of American invasion of 2003. We study how the narratives points are created from the information flows and how through this news events, the French television media judges -and produce meaning-about the involve participants, their relationships and the general meaning of the conflict.
\end{abstract}

Keywords: Television, France, Iraq, media stories.

1. Traducido desde el francés por Jacqueline Fernández Cellier. 
La narración, jamás éticamente neutra, parece ser el primer laboratorio de juicio moral.

Ricœur P. (1990). Símismo como otro, París, Seuil

Si bien las narraciones mediáticas son, al igual que todas las otras narraciones, "un laboratorio del juicio moral", es conveniente considerar que no hacen más que representar los hechos, a menos que se le atribuya a la representación una doble función, la de la repetición, la de la representación en el modo simbólico, y la del ordenamiento de una realidad por esencia caótica o confusa, mediante la construcción de una trama. Las narraciones mediáticas, así como las otras narraciones, se estructuran según la doble dimensión de la mímesis y del mythos. Sin embargo, el poder del efecto de realidad de las imágenes de información televisada junto con la temporalización particular de la transmisión en directo o en diferido muy próxima a los hechos, perturba este equilibrio propio de las narraciones de estilo más clásico. En adelante, la mímesis oculta no solamente el mythos, sino que se anula como tal, para confundirse con "la institución de una realidad en estado bruto" (De Certeau, 1990). Ahora bien, este juego de manos no es solamente creador de una ilusión, tiene consecuencias en cuanto a la forma en que el público interpreta y juzga los acontecimientos y situaciones que hace suyos. Del mismo modo, más que nunca, es necesario prestar particular atención a las narraciones de información televisivas. Este trabajo de observación no se refiere únicamente a los documentos que podrían clasificarse en la categoría del discurso narrativo en oposición a otras categorías de discurso, ya que algunos fragmentos del discurso narrativo yuxtapuestos no constituyen una trama en el sentido de Paul Ricoeur, les faltan los atributos de concordancia, totalidad y completud, así como una dinámica narrativa (Ricoeur, 1983). Por esto es importante hacerse la siguiente pregunta: supongamos un tema de actualidad dado, aquí, nos referiremos al tema iraquí en 1998 en el canal francés France 2 y en el canal franco-alemán ARTE. ¿A partir de cuándo se puede considerar que las noticias que informan sobre este tema se funden en una narración? ¿Según qué modalidad de cohesión creadora de concordancia? ¿A través de qué dinámica narrativa? El análisis de las etapas en que las noticias se suceden unas a otras sin relación entre ellas y el de los períodos donde ellas se condensan en el plano narrativo, debe abrir el camino a una reflexión más amplia sobre la manera en que estos tratamientos mediáticos disponen de marcos de interpretación y de juicio de los acontecimientos y de las situaciones de actualidad.

Diversos trabajos de investigación y publicaciones dedicadas a la cobertura de las guerras de 1991 y 2003 por las cadenas de televisión francesas, permitieron poner en evidencia la especificidad y las diferencias de tratamiento entre dos operaciones militares muy mediatizadas. Se ha dicho todo o casi sobre la guerra del Golfo de 1991, de lo cual se recordará principalmente el rol decisivo de los actores políticos y militares americanos para enmarcar la cobertura mediática al inicio y preformar la narración de las operaciones militares tanto a través de las conferencias de prensa y de los pools como a través de un trabajo realizado en colaboración con diversas empresas de comunicación. Confrontada a la transmisión en 
directo y a la capacidad de CNN, la censura tradicional de las fuerzas armadas se transformó en operación de autopromoción. Así, la narración mediática de las cadenas de televisión francesas, apoyada en la de CNN y obligada por las condiciones derivadas del compromiso nacional, se estructuró según la perspectiva del proceder de los actores dominantes, no según la del padecer de las víctimas iraquíes. Representaba un horizonte de esperanza en el cual la victoria de las fuerzas aliadas contra Irak debía servir de base para la edificación de un nuevo orden mundial. La cobertura mediática de la guerra, a pesar de muchas críticas internas, se basaba esencialmente en la narración de una acción militar considerada desde el lado de los vencedores, no como la narración de un acontecimiento propiamente tal. Estructuraba una adherencia entre las intenciones de los actores que dominaban la situación y las expectativas de los telespectadores (Arquembourg, 2003).

Más compleja es la cobertura de las operaciones de 2003. Presentada como una segunda guerra del Golfo, el conflicto no requería de parte de los medios franceses el mismo apoyo al dispositivo de control como a las intenciones de los beligerantes, ya que Francia había rechazado comprometerse en el plano militar. Oponiendo su veto en el Consejo de Seguridad de las Naciones Unidas, el gobierno francés fue más allá, manifestando su oposición a la decisión de intervención americana. En este sentido, no había ningún obstáculo para sostener debates ni confrontar distintos puntos de vista sobre el conflicto. La mayoría de las cadenas de televisión preparó cuidadosamente lo que sería el ángulo de ataque de la cobertura a venir, considerando la lección aprendida a partir de los resbalones mediáticos de 1991. La regla fue tomar distancia de los documentos provenientes de fuentes oficiales tanto americanas como iraquíes. Pero esta prudencia tuvo también sus efectos perversos, que consistieron en sospechar de las intenciones que estaban tras toda producción de documentos controlada por cualquier autoridad. Por ejemplo, denunciar la visita organizada a un hospital iraquí, habría tenido, en contraparte, que acompañarse de interrogatorios serios, incluso investigaciones reales sobre la cantidad de muertos iraquíes. En realidad, la cobertura televisiva francesa osciló constantemente entre dos perspectivas. La primera consistía en tomar distancia en relación con la definición de los motivos y de los objetivos señalados por los discursos de George Bush, destruir las armas de destrucción masiva que todavía no habrían sido destruidas y perseguir el terrorismo en Irak. Por cierto, esta toma de distancia se manifestó más como una especie de escepticismo bastante vago que como un cuestionamiento abierto o un trabajo de investigación efectivo. La segunda perspectiva se refiere a la desaparición del régimen de Saddam Hussein. Muy pronto, este objetivo reemplaza al primero; la guerra se vuelve un mal necesario, un medio al servicio de un bien, el acceso de un pueblo a la democracia y a la libertad (Arquembourg, 2006). Así la entrada de las tropas americanas en Bagdad y la destrucción de la estatua de Saddam Hussein constituyeron el punto culminante de las narraciones televisivas francesas. Pero al correr de los meses que siguieron a la fecha oficial del fin de las operaciones militares, el $1^{\circ}$ de mayo de 2003, comenzó a producirse una confrontación entre las intenciones de los vencedores y las consecuencias reales de sus actos. Surgieron nuevos acontecimientos que proyectaron una luz diferente sobre las operaciones de 2003: el escándalo de las imágenes 
de Abou Gharib, ${ }^{2}$ investigaciones retrospectivas sobre la ausencia de armas de destrucción masiva, declaraciones y publicaciones de Hans Blix ${ }^{3}$, suicidio de Kelly ${ }^{4}$, resistencia en terreno. Estas formas de irrupción de verdades obliteradas reforzaban y acompañaban la descripción de una situación que, en el vocabulario periodístico, evolucionaba de "liberación" a "ocupación", luego a "barbarie". La situación que parecía manejarse perfectamente en la primavera de 2003, zozobraba entonces en una creciente indeterminación. Evidentemente, esta constatación es portadora de múltiples preguntas a menudo planteadas por los mismos medios. Del mismo modo, invita al análisis de las narraciones mediáticas y a alejarse de los dos "continentes narrativos" supuestamente autónomos que representan las dos "guerras" de 1991 y 2003, para interesarse en el período intermedio que los separa o más exactamente que los une. Este trabajo tendría el mérito, al menos, de recordar a título informativo, la importancia, la frecuencia y la cantidad de "ataques" aliados en el Golfo durante doce años; permitiría también retomar el hilo de los acontecimientos que condujeron de 1991 a 2003 y cuestionar la forma, por lo menos, discreta, en que las cadenas de televisión informaron sobre esto (Arquembourg, 2004).

\section{La estructura narrativa de un episodio: la crisis preliminar en la operación "Zorro del Desierto"}

El bloque de las noticias relacionadas con Irak que se produjeron durante este período plantea, ante todo, problemas metodológicos, ya que se refiere a doce años de cobertura por los diarios de noticias televisadas. Estos documentos se pueden consultar en la Inathèque ${ }^{5}$ de Francia mediante programas específicos. El primer trabajo del cual este corpus fue objeto consistió en señalar fases, secuencias o ciclos, tramas y desenlaces temporales dentro de un amplio conjunto de informaciones. Una de estas fases llama particularmente la atención: se trata de la operación Zorro del Desierto, entre noviembre y diciembre de 1998. Ella juega un rol decisivo, ya que enfrenta directamente al gobierno iraquí y a los inspectores de la Comisión Especial de Naciones Unidas para Irak (UNSCOM) sobre el tema del acceso de los expertos a los sitios presidenciales. La crisis que surge en terreno por la expulsión de los inspectores de la ONU el 13 de noviembre de 1997, adquiere dimensión internacional rápidamente y provoca durante el mes de febrero de 1998, múltiples intervenciones de diversos jefes de Estado así como del presidente del Consejo de Seguridad de ONU, lo que esboza ya las divisiones diplomáticas de los debates preparatorios de 2003. El episodio es entonces importante, tanto desde el punto de vista de las relaciones y tensiones entre diferentes Estados, como de la atribución de roles

2. Centro de detención estadounidense en Irak, del cual se denunciaron abusos y torturas contra los prisioneros por parte de las milicias norteamericanas a fines de 2003 y comienzos de 2004 (N. del E.).

3. Diplomático sueco, a la sazón Comisionado de las Naciones Unidas para la Inspección de Armas de Destrucción Masiva (N. del E.).

4. Científico británico involucrado en la inspección y búsqueda de armas nucleares y biológicas en Irak (N. del E.).

5. Centro de consulta de medios audiovisuales franceses (N. del T.). 
específicos de ciertos actores internacionales. Constituye también un momento crucial entre el período precedente, durante el cual los ataques aliados eran esencialmente en represalia por las acciones militares de Saddam Hussein contra los chiítas en el sur y los kurdos en el norte, y el período siguiente, durante el cual se asiste a la escalada de tensiones entre Irak y la ONU por el tema de las inspecciones. Esta vez, el asunto que está en el centro del conflicto es únicamente la misión de los inspectores de la ONU y la búsqueda de armas de destrucción masiva. De cierta manera, éste anticipaba las acciones de 2003. Al parecer nunca se puso verdaderamente fin a la crisis propiamente tal, según demuestran los recurrentes ataques americanos durante el año 1999. Quizás también se debe revisar, en este segundo plano, el rol de los atentados del 11 de septiembre de 2001 en la designación de Irak como blanco de una nueva intervención militar.

No es evidente aplicar la noción de narración al informe de la operación Zorro del Desierto. Ciertamente, se puede definir fácilmente si tal o tal reportaje, tal o tal transmisión en directo responde o no al discurso narrativo, pero decir que el conjunto de estos documentos puestos uno tras otro configura una narración en el sentido en que Paul Ricoeur habla de construcción de trama dotada de un inicio, un medio y un final, supone que se tomen ciertas precauciones. Las guerras de 1991 y 2003 son más fáciles de identificar como tales, ya que ellas disponen, en particular, de un inicio anunciado anticipadamente, se orientan resueltamente hacia un final proyectado y terminan oficialmente en una fecha precisa, incluso si este final fue contradicho cada vez por la realidad en terreno. De cierta manera, se puede decir que desde el punto de vista de la acción, han sido anticipadas en forma de narración. Además, si bien las dos guerras han sido objeto de una mediatización espectacular, el volumen de informaciones relacionadas con Irak disminuye notoriamente durante los años que siguieron a la guerra del Golfo. Así, la suma de apariciones dedicadas por TF1 o France 2 al conflicto de 2003 aumenta por momentos a 500 o 550 y el volumen global de la información de todas las cadenas, comprende 6000 apariciones. Este volumen global es mucho más bajo durante el período intermedio, alcanza apenas a un centenar de apariciones en 1995, luego aumenta un poco en 1996 y 1997 hasta 500 apariciones en 1998. Luego disminuye considerablemente en 1999 y 2000 hasta su nivel más bajo y retoma ligeramente en 2001.

De forma general, el interés por el problema iraquí ha disminuido considerablemente en los periódicos televisados durante este período, lo que tiene consecuencias al crear una trama de los acontecimientos, ya que éstos surgen a menudo de manera discreta como breves o reportajes situados al final de las noticias televisadas. Existe también una relativa disparidad entre las cadenas que siguen muy de cerca el problema iraquí, a menudo a través de pequeños formatos televisivos como el Ocho y medio de la cadena ARTE y las principales cadenas no especializadas que cubren la situación de manera más selectiva, más irregular e intermitente. A primera vista parece que se relaciona con lo que Paul Ricoeur llama una narración de episodios, encadenando los hechos a lo largo de una sucesión cronológica sin que sea posible observar los fenómenos de concordancia y de dinámica narrativa que caracterizan la construcción de 
la trama. Por lo tanto, estaríamos en los límites de la narración confrontada con una especie de desmoronamiento narrativo. Sin embargo, se puede constatar que sobre estas olas de información surgen bloques, a veces modestos, como atolones, a los cuales se aplicarán los criterios ricoeurianos de composición de narraciones para observar cómo espacios narrativos coherentes se han sucedido en forma discontinua y en alguna medida por resurgimiento, durante estos años.

\section{El inicio}

La asignación de un inicio a este episodio sólo puede hacerse de manera retrospectiva. El 13 de noviembre de 1997, Saddam Hussein expulsa a los inspectores de la UNSCOM porque juzga que el grupo de expertos incluye demasiados americanos y que éstos se dedican a actividades más cercanas al espionaje que a la misión que les ha sido confiada por la ONU. Se niega también a abrirles el acceso a sus palacios presidenciales. Los inspectores sospechan, en efecto, que estos edificios esconden depósitos de armas de destrucción masiva, en bunkers subterraneos. De diciembre de 1997 a febrero de 1998, se desencadena una crisis internacional, cuyas etapas son cubiertas por fragmentos dispersos en las diferentes cadenas de televisión. Se observará que, si bien ARTE informa de cómo se desencadena el conflicto en terreno, principalmente durante el mes de enero, France 2 sólo trata la situación a partir del momento en que éste adquiere dimensión de crisis internacional, es decir, a partir del mes de febrero.

En un primer tiempo, la expulsión de los seis inspectores de la ONU el 13 de noviembre de 1997 no parece ser el inicio de un episodio por venir, sino más bien como un avatar, un nuevo capricho de Saddam Hussein en el marco de las conflictivas relaciones entre Irak y Estados Unidos. Poco a poco se desarrolla una situación complicada, de la cual informa ARTE insertándola ya en un período:

Un equipo de expertos encargado de controlar el desarme del país, dejó Irak esta mañana, sin haber cumplido su misión. Desde hace varios días, los iraquíes se negaron a proporcionar escolta a los seis miembros del equipo. La razón invocada: este equipo incluía demasiados americanos y británicos.

A partir del dieciséis de enero, la situación se describe en forma reiterada: "Bagdad prohíbe nuevamente que una misión de la UNSCOM dirigida por un americano acceda a sus sitios sensibles", "Las razones invocadas son siempre las mismas". El comentario lleva a pensar que se está repitiendo un escenario cíclico negando anticipadamente el surgimiento de un nuevo fenómeno. Este remite implícitamente a un campo de la experiencia en el cual encontramos otros rechazos de parte de los iraquíes, pero también el inicio de una situación que dura "desde hace varios días" sin que los medios le hayan prestado mayor atención.

A fines del mes de enero, diferentes instancias internacionales tratan de intervenir para desbloquear la situación: Rusia, Francia, la Unión Europea. A partir de este momento, y sobre todo a inicios de febrero, France 2 abre un espacio considerable al tema iraquí en las noticias 
televisivas de la tarde, es decir a partir del momento en que la crisis se puede considerar como una crisis internacional. Paradojalmente, se puede observar que si bien efectivamente estas diferentes intervenciones constituyen, en la práctica, intentos de desenlace, desde el punto de vista narrativo ellas actúan más bien como una trama, un momento en que la acción adquiere una dimensión que la hace digna del interés público y en que puede darse un vuelco a la situación.

\section{Nudo y primera tentativa de resolución}

A partir de entonces, se puede observar la ejecución de una auténtica construcción de trama que se desarrolla paralelamente en dos escenarios: el escenario diplomático y el de las maniobras militares. Esta repartición binaria organiza la sucesión de noticias dándole una relativa coherencia. A menudo, los periodistas de France 2 describen el despliegue de las fuerzas americanas en el Golfo unido a la posición intransigente de los Estados Unidos como "un engranaje" o "una máquina infernal". Pero la relación entre los escenarios diplomático y militar se manifiesta primero como una yuxtaposición de acciones paralelas. "Jacques Chirac recibirá al ministro iraquí de Relaciones Extranjeras mientras que en el Golfo, los americanos continúan movilizando tropas con ayuda de sus aliados más fieles, Gran Bretaña y Australia” anuncia el presentador, Daniel Bilalian, el 16 de febrero. Al día siguiente, comenta la actualidad en estos términos: "El Secretario General de las Naciones Unidades, Kofi Anan, vuela hacia Bagdad, esto en lo que respecta a la diplomacia; paralelamente, siguen llegando las tropas al Golfo. Washington envía baterías de misiles Patriot a Israel para garantizar su defensa”.

La configuración narrativa no solamente informa sobre esta doble efervescencia, sino que también asigna roles a los diferentes actores. En el plano diplomático, es claro que el Consejo de Seguridad de las Naciones Unidades está dividido y que particularmente Rusia y Francia están en desacuerdo con la política desarrollada por Estados Unidos y Gran Bretaña en el Golfo. Esta división fue perceptible desde el mes de octubre de 1997 en una corta emisión de imágenes en el diario ARTE:

Por primera vez la ONU, Francia, Rusia y China se abstuvieron durante la votación de una resolución del Consejo de Seguridad en Irak, un texto que amenaza a Bagdad con sanciones económicas. La política de aislamiento de Estados Unidos hacia Irak, Libia e Irán se pone cada vez más a prueba.

Ahora bien, estos roles se configuran de una manera totalmente distinta en France 2 en febrero de 1998, cuando afirma que los cinco miembros del Consejo de Seguridad "se habían repartido el trabajo: parte militar, Estados Unidos y Gran Bretaña; parte diplomática, Francia y Rusia, y en el medio, China, hostil a los golpes pero inactiva”. Entonces se vuelve difícil decir si las acciones desarrolladas en los dos escenarios son concurrentes o complementarias y si Estados Unidos actúa de acuerdo con la comunidad internacional o según una orientación independiente de lo que la diplomacia internacional trata de retardar, incluso frenar. La 
misma definición de las relaciones de fuerza que oponen los diferentes protagonistas también evoluciona durante estos dos meses. En el mes de enero, los noticiarios de ARTE describen una parte de la competencia de fuerza entre Irak y la ONU. Pero el 28 de enero, Bill Clinton, en un discurso en el Congreso de Estados Unidos, ordena a los iraquíes a no "desafiar la voluntad del mundo". A partir de este momento, France 2 presenta el conflicto como "una crisis entre Irak y la comunidad internacional". Luego, poco a poco, toma aspecto de una oposición frontal entre Irak y Estados Unidos que los reportajes de los periodistas personalizan en forma caricatural bajo la forma de un enfrentamiento entre Bill Clinton y Saddam Hussein. El 22 de febrero, Maryse Burgot pone en escena esta "pelea entre jefes" en los siguientes términos:

Los americanos han desencadenado una especie de máquina infernal; como nos decía un diplomático europeo, son de alguna manera prisioneros de esta máquina que ellos mismos han desencadenado. Para detener esta máquina necesitan poder decir "hemos ganado, hemos logrado la rendición de Saddam Hussein". Es la única forma en que Bill Clinton recuperará su prestigio con este ejército movilizado en el Golfo. Ahora bien, lograr la rendición de Saddam Hussein es obtener un acuerdo del $100 \%$ a la visita de los sitios presidenciales. Pero en este caso sería Saddam Hussein quien se desprestigie. Por lo tanto, la esperanza de paz depende de estos dos países, Irak y Estados Unidos, quienes, de una u otra manera, desean recuperar el prestigio.

Si bien esta teatralización de fuerte influencia psicológica no carece totalmente de fundamento, Hans Blix, en su obra, observa que la dignidad y la soberanía nacional de Irak no han sido lo suficientemente salvaguardadas, tanto por los expertos de la UNSCOM como por Estados Unidos, mas no por ello dejó de ser una síntesis (Blix, 2004). Ahora bien, esta síntesis que podía aclarar en forma interesante la situación, no fue objeto de ningún comentario. La explicación suponía explorar el trasfondo institucional relacionado con los vínculos particulares entre Estados Unidos y los expertos de la UNSCOM, que nunca fueron abordados por los medios. En efecto, las tensiones que enfrentan en la época a la UNSCOM con la AIEA, tanto en cuanto a los métodos de trabajo en terreno como al análisis de la situación, no son mencionadas en los medios franceses y constituyen el punto ciego del tratamiento televisivo en ese período. ¿Aparece la UNSCOM en este caso como una emanación de la ONU sin que las complejas relaciones entre estas dos instituciones sean examinadas? Esta redefinición de las relaciones de fuerza tiene por consecuencia reconfigurar el conflicto que, a partir de ahora, no enfrenta más a Irak y la ONU sino a Estados Unidos e Irak, lo que, por una reacción en cadena, transforma el rol de las Naciones Unidas que, a partir de ahora, quedan en situación de árbitro. A este respecto, France 2 hace hincapié en que el arbitraje se realiza esencialmente en sentido único, ante Irak, en el sentido de las exigencias americanas. En ciertos reportajes, el Secretario General de las Naciones Unidas, parece ni más ni menos que encargado de una misión del gobierno norteamericano ante Irak, como cualquier diplomático de ese país. Así, el 20 de febrero, un primer contacto entre Kofi Anan y Tarek Aziz distiende un poco la situación. 
Esta tarde, para hacer hincapié en la relativa distensión, expertos en desarme de los Estados Unidos pudieron penetrar y visitar sin impedimentos ciertos sitios presidenciales iraquíes. Ahora bien, es justamente la negativa de Saddam Hussein de abrir todos sus edificios a los inspectores internacionales lo que originó la crisis. Un primer paso lejos de las exigencias de Bill Clinton renovadas esta tarde en un mensaje a las naciones árabes: un acceso libre e incondicional a estos sitios. Le corresponde a Kofi Anan convencer a los iraquíes, de lo contrario hablarán las armas.

En la intriga que se trama en las cadenas francesas, la ONU no aparece en el rol de una instancia supranacional que vela por el respeto de la aplicación de acuerdos internacionales, que es su función en relación con el control de las $\mathrm{ADM}$, sino más bien como un árbitro, incluso un mediador entre naciones en conflicto.

De este modo, el nudo de la acción en el plano narrativo aparece como el momento en que la situación es calificada, en que los roles de los principales actores son distribuidos, en que la naturaleza de sus relaciones se define. Ahora bien, a partir de este punto se puede designar el inicio de manera retrospectiva. La expulsión de los inspectores propiamente tal no es un inicio, ya que el encadenamiento de hechos y circunstancias que provocará no se conoce con anticipación. Es la principal diferencia entre las narraciones mediáticas y las narraciones ficticias: los que cuentan la historia ignoran su final. La sucesión de noticias sólo se configura a partir del momento en que se hace evidente que una intriga se está tramando. A diferencia de las narraciones de guerra de 1991 y 2003 cuyo desarrollo narrativo había sido pensado y preparado por los principales actores, los atolones narrativos del período intermedio se estructuran a partir del medio de la historia. Lo que surge entonces tiene efecto retroactivo en el pasado haciendo aparecer un inicio y adelanto hacia el futuro, en forma de un horizonte de esperanza y fines proyectados. En relación con las narraciones de vida, Paul Ricoeur insistió en esta inversión del efecto de contingencia, en efecto de necesidad retrospectiva: "Como simple circunstancia [el acontecimiento] se limita a abandonar las expectativas creadas por el curso anterior de los acontecimientos, es simplemente lo inesperado, lo sorpresivo, sólo llega a ser parte de la historia después de ser comprendido, una vez transformado por la necesidad en alguna medida retrógrada que procede de la totalidad temporal llevada a su término. Ahora bien, esta necesidad es una necesidad narrativa cuyo efecto de sentido procede del acto que configura como tal; esta necesidad narrativa transmuta la contingencia física, adversa de la necesidad física, en contingencia narrativa, implicada en la necesidad narrativa” (Ricoeur, 1990). La construcción de tramas de situaciones del tipo de la que sirvió de preludio a la operación Zorro del Desierto, nunca se configura a priori y sólo toma cuerpo en forma progresiva organizando poco a poco su propia necesidad.

\section{Organización general de la narración}

La crisis parecellegar a su término a fines del mes de febrero de 1998, gracias a la intervención de Kofi Anan. Esta tentativa de resolución es descrita por los medios como un triunfo y el retorno del Secretario General a Nueva York como el de un héroe. Entonces, el asunto iraquí parece 
haberse borrado de las noticias televisivas hasta el mes de noviembre. Por ejemplo, en el mes de julio, no figuraba en ninguna de las noticias televisivas de France 2 y ARTE. Sin embargo, algunas noticias dan cuenta de ciertas dificultades: la entrega del informe Butler, en el mes de junio, la solicitud de Irak para levantar las sanciones económicas, en el mes de agosto. A partir del $1^{\circ}$ de noviembre, se reanudan dramáticamente las tensiones cuando Irak rompe relaciones con la UNSCOM. El ciclo de amenazas y de intervenciones diplomáticas recomienza; entonces y una vez más, la intervención de Kofi Anan es positiva, ya que los inspectores retoman su camino a Bagdad el 17 de noviembre. Nuevamente la crisis parece haberse resuelto y no se habla más del tema de Irak en las noticias televisivas. Pero la publicación del informe Butler el 16 de diciembre rompe definitivamente este frágil equilibrio. Esta vez, Estados Unidos no le da tiempo de intervenir a la diplomacia de la ONU, ataca a Irak durante cuatro días desde el 17 al 20 de diciembre de 1998.

El relato mediático de esta crisis desde el otoño de 1997 a diciembre de 1998, se organizó entonces por pequeños bloques discontinuos, siendo las dos fases más importantes el nudo y el primer intento de desenlace de Kofi Anan en febrero de 1998 y los ataques de fin de año. En France 2, en particular, el relato construye dos ciclos de acción y se distiende entre los dos. En sí, el hecho de que los medios centren la atención en estos dos episodios ya constituye un juicio. Es abordar la crisis desde el punto de vista de los intentos de resolución que aplican los miembros del Consejo de Seguridad de las Naciones Unidas, la diplomacia en primer término, luego las operaciones militares. Esta estructura narrativa constituye por sí sola una lección y una amenaza para Irak.

\section{Las conexiones lógicas y temporales}

Dos tipos de conexiones juegan un rol esencial en la constitución de la concordancia narrativa: las conexiones lógicas que organizan las relaciones de causa y efecto y las conexiones temporales. Referente a esto se puede definir, según John Dewe, toda narración como una operación de juicio. "Juzgar es determinar, determinar es ordenar y organizar, relacionar en forma definida. El orden temporal está instituido por ritmos que comprenden periodicidades, intervalos y límites, todos interrelacionados" (Dewey, 1993). Queda por saber cómo los medios han interpretado la situación, es decir, qué vínculos de causalidad y qué conexiones temporales, se han tejido en torno a las diferentes expulsiones de los inspectores realizadas por Saddam Hussein.

Un documento del 21 de enero de 1998 en ARTE informó que Richard Butler, el jefe de los inspectores de la UNSCOM, se reunió con Tarek Aziz al no haber podido visitar los sitios presidenciales. El periodista agrega el siguiente comentario: "El tema de los sitios presidenciales está por lo tanto congelado, desde ahora está vinculado al levantamiento del embargo petrolero (...) El embargo que sufre Irak desde 1990 sólo podrá ser levantado cuando la UNSCOM certifique que Bagdad no posee armas químicas, biológicas o nucleares". La relación entre el tema del embargo y el de las armas de destrucción masiva está omnipresente, más aún cuando los medios han informado ampliamente sobre los efectos destructivos en la población iraquí, 
principalmente en los niños. Pero la circularidad del informe de causa y efecto entre los dos problemas no se examina ni se explicita. En 1996, el embargo que se había establecido después de la guerra del Golfo se flexibilizó, permitiendo que Irak volviera parcialmente al mercado petrolero. El 20 de mayo de 1996 se firmó un memorándum de acuerdo estipulando que las sanciones económicas sólo serán levantadas cuando el Consejo de Seguridad tenga la certeza de que Irak ya no posee armas nucleares y químicas. Para la ONU, Irak debe deshacerse totalmente de sus armas de destrucción masiva con el fin de que se levante el embargo, pero para Irak, es necesario que las sanciones económicas desaparezcan para que los expertos tengan acceso a todos los sitios, principalmente a los edificios presidenciales. La manera en que cada parte instrumentaliza el tema del embargo en su propio beneficio se vuelve rápidamente muy confusa en los reportes mediáticos. Así, las noticias que anuncian las salidas sucesivas de los inspectores no precisan si los expertos han decidido interrumpir las inspecciones por su propia voluntad, de lo que se subentiende el embargo durante ese tiempo, o si han sido expulsados por las autoridades iraquíes, lo que significa que el levantamiento del embargo se vuelve una condición previa a su eventual retorno.

A estas conexiones causales explícitas, aunque a menudo confusas, se agrega una gran parte implícita. Así, el 20 de febrero, un reportaje de France 2 propone hacer un balance del armamento iraquí. En el capítulo de las armas biológicas, las imágenes muestran una fábrica y un vertedero en el cual se vierten cantidades impresionantes de un producto no identificado. El comentario que acompaña las imágenes precisa que

es el informe más preocupante, el más difícil de verificar. Ejemplo, esta fábrica de producción de alimento para animales también había sido diseñada para fabricar miles de litros de muerte instantánea, en forma de Botulina o Antrax, será finalmente destruida por la ONU, pero sólo después de la sorpresiva deserción del yerno de Saddam Hussein y revelaciones que muestran que durante cuatro años, Bagdad había logrado importar cepas mortales bajo las narices de la ONU.

La duda que surge aquí se basa en un pseudo-trabajo de investigación: esta fábrica queles mostramos, las revelaciones del yerno de Saddam Hussein. El valor indicativo de las imágenes y la forma del reportaje muestran un tipo de eficacia formal que viene a apoyar una producción de pruebas de por sí bastante frágil. En efecto, si bien la fábrica a la cual se refiere fue destruida, las imágenes que la muestran, en revancha, no tienen fecha. En cuanto al yerno de Saddam Hussein, nada indica en qué circunstancias pudo haber hecho una revelación de este tipo.Ahora bien, el general Hussein Kamel, quien estuvo en Jordania en agosto de 1995, era responsable de los programas de armamento iraquí. Declaró públicamente que todas las armas químicas y biológicas habían sido destruidas por orden suya en 1991. El gobierno iraquí aprovechó para proporcionar numerosos documentos a la ONU que revelaron informaciones sobre lo que habían sido los programas de armamentos antes de la guerra del Golfo, al mismo tiempo que imputaba a Hussein Kamel la responsabilidad de haberlas escondido. Pero Hans Blix observa a 
este respecto que "aun cuando estas revelaciones fuesen importantes para el conocimiento y la comprensión de los programas y acciones pasadas de Irak, éstas no llevarían al descubrimiento ni a la destrucción de otras armas" (Blix, 2004). En el reportaje, ninguna precisión indica la procedencia exacta de las revelaciones. El comentario deja suponer que si se pudo realizar importaciones ilegales en el pasado, nada impide que se vuelvan a hacer en el futuro. La alusión es mucho más clara en la conclusión del reportaje que muestra cadáveres de mujeres y de niños muy pequeños. En forma ensordecedora, una frase musical lúgubre se superpuso sobre las imágenes. El comentario se orienta entonces hacia la comprobación de la presencia de tales armas en la región pero se termina precisando que "sólo Irak bajo Saddam Hussein hizo uso de ellas”. En realidad, la música y las imágenes colman la ausencia de investigación efectiva sobre un asunto difícil, ciertamente, pero que podía ser apoyado mediante referencias precisas a los sucesivos diferentes informes de los inspectores de la ONU.

En la elaboración de la concordancia y de la dinámica narrativa del relato, las conexiones temporales juegan un rol tan decisivo como las conexiones causales. El 14 de febrero, un reportaje establece el calendario de las negociaciones diplomáticas que deben tratar de disuadir los ataques militares.

Mañana, el ministro iraquí de Relaciones Exteriores se reunirá con Jacques Chirac en París, para entregarle la respuesta de Saddam Hussein después de la visita del emisario francés. La misma tarde, Bill Clinton se dirigirá al pueblo americano, en un discurso solemne para justificar el ingreso al Golfo: el viernes 18 de febrero, el Secretario General de las Naciones Unidas debería reunirse, siempre en París, con el ministro iraquí de Relaciones Exteriores. Kofi Anan podría luego dirigirse a Bagdad para una última misión diplomática. En principio, no hay acción militar antes del fin de la tregua olímpica. Por otro lado, el Congreso de Estados Unidos no se reunirá hasta el 24, entonces podría votar una resolución de apoyo a una intervención militar. Es sólo en ese momento que los americanos podrían definitivamente dar la espalda a la vía diplomática.

El calendario esboza un horizonte de esperanza e impulsa un ritmo a la acción. Pone en evidencia un conjunto de convergencias y de imbricaciones entre noticias que, de otro modo, no obedecerían a una sucesión cronológica. A este respecto, constituye un proceso de nudo de la trama en el plano narrativo. No es indiferente que este procedimiento se elabore en el futuro y en condicional y no en pasado como en una narración ficticia. Casi siempre, la ausencia de final conocido anticipadamente obliga a los periodistas a elaborar la temporalidad de las narraciones mediáticas a partir de finales temporales, anunciados o proyectados. Aquí, la fecha tope del 24 de febrero se da como el momento a partir del cual una de las dos vías, diplomática o militar, deberá hacerse prevalecer sobre la otra. Es a la vez sobre este punto del futuro que todas las acciones futuras convergen y es a partir de este punto que forman retrospectivamente un bloque narrativo coherente.

A partir de entonces, los comentarios periodísticos no cesarán de mostrar una carrera contra el reloj entre las negociaciones diplomáticas y el despliegue militar en terreno. Insisten en 
"el alza en poderío del dispositivo militar", en "los progresos de la diplomacia"; crean suspenso en torno al "intento de la última oportunidad". Esta progresión dramática va en dirección de un desenlace, pero construye implícitamente un relato que quiere que la diplomacia se interponga entre el rechazo obstinado de Irak y el deseo norteamericano de responder por la fuerza de las armas. De esta forma, el conflicto que inicialmente oponía a las autoridades iraquíes a los inspectores de la ONU, cambió definitivamente de naturaleza.

\section{Del relato como operación de juicios}

Una vez más, a diferencia de las guerras de 1991 y 2003, el inicio del relato de la crisis de 1998 no es claro, ni programado, ni anunciado anticipadamente. Lejos de ser una apertura, emerge sin provocar ninguna reacción ni comentario particular de parte de los medios, digamos que se produce incidentalmente, en forma de repetición. Sólo se manifiesta como el inicio de una crisis internacional más tarde, en el momento preciso en que esta crisis se declara. Para las cadenas no especializadas como France 2, este nudo sólo surge cuando la crisis toma una dimensión internacional, convoca varios escenarios y una pléyade de actores. Entonces, es la naturaleza de la problemática situación tal cual se plantea a inicios del mes de febrero de 1998 la que determina el inicio y el final: el 13 de noviembre y el 24 de febrero. Encontramos ahí una de las características que Dewey da a la narración: "Los inicios y los finales están relacionados con la intención objetiva planteada en la investigación por la problemática calidad de una situación determinada" (Dewey, 1993). Los inicios y finales no son claros. En el ejemplo que nos interesa, el relato no puede estructurarse ni a partir de un hecho que surge en forma violenta ni, como en el caso de los relatos ficticios, a partir de un final conocido anticipadamente por el narrador. En el período que separa 1991 y 2003, las noticias relacionadas con Irak se suceden sin vínculo entre ellas. Por momentos, se configuran nudos y desenlaces, generalmente a partir del medio de la historia. En cuanto al final, éste se proyecta en forma anticipada al relato y como fuera de él. Crea un horizonte de esperanza portador de valores o juicios. En febrero de 1998, se trata de la esperanza de un arreglo pacífico del conflicto; en diciembre, se tratará de una amenaza en relación con Irak, luego de una demostración de fuerza. El final, anticipado, esperado o temido, constituye un punto de adherencia entre el relato televisivo y su público. Clave de bóveda de la arquitectura narrativa de los medios, une la diversidad de los informes creando un foco de convergencia, proporciona una orientación al relato a partir de la cual se elabora una dinámica narrativa. De hecho, la descripción de una situación problemática a partir de su nudo invita al público a una dialéctica de la anticipación y de la retrospección que constituye el relato. Tomado en estemovimiento, la narración nunca es neutra ya que realiza un juicio. Así, la elección de cubrir la crisis sólo a partir del mes de febrero en lugar de a partir del mes de enero, no deja de tener incidencia en la definición de los términos del conflicto y en la atribución de roles de los actores. Entonces, el relato asigna roles, construye identidades, pone en escena relaciones entre actores y los califica, elabora conexiones causales y temporales que, en conjunto, incorporan elementos dispersos. El hecho de que los relatos mediáticos dispongan los marcos de interpretación de 
los acontecimientos y de las situaciones se hace todavía más manifiesto cuando se prolongan recurriendo al juicio de los telespectadores, entrelazando así dos modalidades de la operación de juicio, la que es constitutiva de los relatos y la que emerge en respuesta a los acontecimientos y las situaciones públicas. Es el caso del 22 de febrero en France 2. Al final de las noticias, la presentadora anuncia que la cadena de televisión y el diario Le Figaro se asociaron para lanzar un amplio operativo de medición de "la forma en que los franceses reaccionan frente a la crisis iraquí". La primera pregunta es la siguiente: " $i \mathrm{Si}$ las negociaciones fracasan, esto se debe: a la mala voluntad de Irak (49\%)? ¿A la de Estados Unidos (16\%)? ¿Las dos (24\%)?” Es verdad que recurrir a "la mala voluntad" de los socios parece coherente con la personificación de un conflicto en el cual ninguno de los dos campos parece querer "perder el prestigio". El asunto opone a los dos protagonistas, que son Irak y Estados Unidos, y la ONU sólo es citada en forma alusiva. Reduce el relato a su quintaesencia, la del conflicto entre dos naciones que se desarrolla en un segundo plano incierto, ya sea que se trate de relaciones entre Irak y los inspectores de la UNSCOM, de intereses institucionales relacionados con la UNSCOM y la Autoridad en Investigación Agrícola (AIEA) o de la relación entre el embargo y las inspecciones. De hecho, el relato de la crisis promueve también otros relatos que se supone son conocidos del público y remite, en un comienzo, a un campo de la experiencia a lo menos opaca, pero que parece ser objeto de consenso. ¿Entonces, qué es lo que se mide así, la reacción a la crisis iraquí o al relato de la crisis iraquí? ¿Los términos del sondeo no hacen más que reactivar la interpretación de la situación de crisis en los términos mismos de la construcción de su trama televisiva?

Son estas construcciones de trama esporádicas las que aún permiten aplicar la noción de relato a los informes de situaciones y acciones que no interesan a los medios en forma prioritaria. Es verdad que los acontecimientos de abril de 2003 y sus consecuencias invitan también a recrear conexiones en la sucesión de los episodios análogos a los del Zorro del Desierto y a insertarlos en lo que sería un relato más amplio en el cual sería interesante observar los sucesivos fenómenos de puesta en evidencia y ocultación, determinados por diferentes episodios. Entonces, nos podríamos preguntar cómo la puesta en relato de la segunda guerra del Golfo logró obliterar toda relación con las operaciones militares del período 1991-2003, sin aparecer como el desenlace de éstas, y cómo los acontecimientos del 11 de septiembre determinaron un brusco vuelco, quebrantando la complejidad de las intrigas tramadas entre 1998 y 2001.

\section{Referencias bibliográficas}

Arquembourg,J. (2003). Le temps des événements médiatiques. Bruxelles: Ina-de Boeck.

(2004). «Les récits sont des pièges». En: Armes de communication massives. París: CNRS.

(2006). «Un récit sous tension: la guerre en Irak sur les chaînes de télévision françaises».

Strasbourg: Actes du colloque sur linformation dans les conflits.

Blix, H. (2004). Irak, les armes introuvables. París: Fayard. 
De Certeau, M. (1990). L'invention du quotidien. Tm. 1: Arts de faire. París: Gallimard.

Dewey, J. (1993). Logique, la théorie de l'enquête. París: Presses Universitaires de France

Ricoeur, P. (1981). Temps et Récit. Tm. 1. París: Senil.

_ (1990). Soi-même comme un autre. París: Senil. 